\title{
PERCEPÇÕES DE ALUNOS DO CURSO DE SISTEMAS DE INFORMAÇÃO EM RELAÇÃO AO PLÁGIO ACADÊMICO E AÇÕES PARA SUA REDUÇÃO
}

\section{PERCEPTIONS OF STUDENTS OF THE INFORMATION SYSTEMS COURSE IN RELATION TO THE ACADEMIC PLATE AND ACTIONS FOR THEIR REDUCTION}

\author{
Ernane Rosa Martins ${ }^{1}$, Solange da Silva ${ }^{2}$, Ulisses Rodrigues Afonseca ${ }^{1}$, Wendell \\ Bento Geraldes ${ }^{1}$, Luís Borges Gouveia ${ }^{3}$ \\ ${ }^{1}$ Instituto Federal de Goiás - IFG, GO. ${ }^{2}$ Universidade Católica de Goiás - UCG. \\ ${ }^{3}$ Universidade Fernando Pessoa - UFP,. Portugal. \\ E-mail: ernane.martins@ifg.edu.br, solansilva.ucg@gmail.com, urafonseca@ifg.edu.br, \\ wendell.geraldes@ifg.edu.br, Imbg@ufp.edu.pt
}

RESUMO - O plágio é o ato de apresentar como sua uma ideia ou obra de outro autor sem mencioná-la como fonte. Esta prática vem sendo comum no meio acadêmico, principalmente com a facilidade oferecida pelo uso da internet. Este estudo tem como objetivo verificar como os alunos do curso de Sistemas de Informação entendem o plágio e quais as possíveis ações para a redução desta prática nos trabalhos acadêmicos. A pesquisa foi realizada por meio de questionários semiestruturados, utilizando-se de pesquisa e análise descritiva. Os resultados mostraram que os alunos não têm conhecimento pleno do que é plágio, não sabendo identificar os tipos de plágios específicos, o uso correto das citações e a necessidade colocar as citações diretas e indiretas das fontes utilizadas em seus textos.

Palavras-chave: plágio acadêmico; direitos autorais; sistemas de informação.

\begin{abstract}
Plagiarism is the act of presenting as an idea or work of another author without mentioning it as a source. This practice has been common in academia, especially with the ease offered by the use of the internet. This study aims to verify how students of the Information Systems course understand plagiarism and what possible actions to reduce this practice in academic work. The research was carried out through semi-structured questionnaires, using research and descriptive analysis. The results showed that students do not have full knowledge of plagiarism, not being able to identify specific types of plagiarism, the correct use of citations and the need to place direct and indirect citations of the sources used in their texts.
\end{abstract}

Keywords: academic plagiarism; Copyright; information systems.

\section{INTRODUÇÃO}

O plágio consiste em reproduzir indevidamente uma obra de forma integral ou parcial, assumindo a autoria que pertence a outrem, não identificando o nome do autor e a origem da obra. (BARBASTEFANO E SOUZA, 2007). Também se define plágio como sendo a apropriação de ideias ou textos alheios. Existem 
duas formas de plágio: uma é a cópia literal de textos e outra é a cópia de ideias, apesar do autor não repetir as palavras como foram escritas, ele apresenta as mesmas ideias como se fossem suas, inclusive na mesma sequência lógica (WAZLAWICK, 2014).

No Brasil, os direitos autorais são regidos pela lei 9.610 de 19 de fevereiro de 1998. Que diz: "a reprodução não autorizada de uma obra constitui-se em contrafação estando os infratores sujeitos às sanções civis e penais cabíveis". Também tratado no Código Penal sobre os crimes contra a propriedade intelectual, no artigo 184 que diz: "Violar direito autoral: pena detenção, de 3 (três) meses a 1 (um) ano, ou multa". Contudo, a lei diz: "que não constitui ofensa aos direitos autorais à citação de passagens de qualquer obra, para fins de estudo, crítica ou polêmica, desde que indicado o nome do autor e a origem da obra" (BARBASTEFANO; SOUZA, 2007); (WAZLAWICK, 2014).

É permitida a citação de trechos de livros, com a obrigatoriedade da menção ao nome do autor e à fonte pesquisada, segundo os procedimentos estabelecidos pela Associação Brasileira de Normas Técnicas (ABNT), entidade nacional que estabelece os critérios para a elaboração e apresentação de trabalhos acadêmicos. Historicamente, desde o ensino fundamental à universidade, tem se observado a prática de cópias de textos de outros autores, de forma parcial ou integral, omitindo-se a fonte. Com a informatização estas práticas têm-se acentuado, visto as possibilidades que se ampliam com o uso da internet (SILVA, 2008).

Assim sendo, este artigo visa responder a seguinte questão de pesquisa: "Os alunos do curso de Sistemas de Informação entendem o plágio e quais as suas possíveis sugestões de ações para a redução desta prática?". O objetivo deste artigo é verificar junto a alunos do curso de Sistemas de Informação, como estes entendem o plágio e principalmente quais as possíveis ações para a redução desta prática nos trabalhos acadêmicos, utilizando como abordagem de pesquisa 0 método de pesquisa descritiva, conforme orientação da literatura. (GIL, 2008).

Esta pesquisa se justifica, pois segundo Azevêdo, (2006), Vasconcellos, (2007) e Silva, (2008), no Brasil, o plágio é um tema pouco investigado. $\mathrm{Na}$ literatura podem ser destacados alguns estudos tais como: Moraes, (2004); Silva, (2008); Pithan e Vidal, (2012); Vaz, (2006); Albuquerque, (2009); Job, Mattos e Trindade,
(2009); Azevêdo e Tavares-Neto, (2009); Abranches, (2008); Barbastefano e Souza, (2007); Silva e Domingues, (2008); Domingues e Fachini, (2008); Krokoscz, (2011); Ferreira e Persike, (2014) e Guedes e Gomes Filho, (2015).

Este artigo está estruturado com as seguintes seções: a revisão bibliográfica traz os estudos sobre plágio encontrados no meio acadêmico. Na metodologia são apresentados os procedimentos metodológicos de investigação, utilizados na pesquisa. A análise dos resultados obtidos descreve os resultados obtidos neste estudo. Por fim, estão as considerações finais e referências.

\section{REVISÃO BIBLIOGRÁFICA}

\subsection{Plágio e conceitos associados}

O plágio consiste na cópia de trabalho de outros, assumindo o mesmo como próprio, não reconhecendo as fontes ou autores associados com a produção original desse trabalho. De acordo com o dicionário Priberam ( $\mathrm{s} / \mathrm{d}$ ), plágio possui dois significados: "(i) ato ou efeito de plagiar"; e (ii) "imitação ou cópia fraudulenta". Por sua vez, na mesma fonte (Priberam, s/d), plagiar é definido como "copiar ou imitar, sem engenho, as obras ou pensamentos dos outros e apresentá-los como originais". Por sua vez e utilizando a mesma origem, batota é definido como "trapaça no jogo" ou, em sentido figurado "engano, logro" (Priberam, s/d, b). A ideia que se pode realizar em alternativa ao estipulado, algo que seja tomado como o desejado, enganando quem o solicita.

No contexto do ensino superior estes conceitos ainda ganham maior força, pois o trabalho realizado é normalmente suportado pela conjugação de ideias e argumentos próprios, relacionando estes com ideias e argumentos de terceiros. Resulta assim, que um trabalho de natureza académica deve mesmo conter e ser suportado por trabalhos de terceiros, mas com a preocupação de referenciar os autores originais do trabalho e de identificar qual a contribuição original realizada. Tem que existir forma de separar o que é próprio, criado pelo autor e o que é resultado do esforço já realizado por outras pessoas. Desse modo, as fontes de informação devem ser expressas de forma clara e existem normas para citar o trabalho de terceiros: as citações.

Se não for citada a origem do trabalho, da ideia ou parte de texto que é utilizado num trabalho realizado, estamos perante um plágio. 
De facto, tal como é referido no local Web Brasileiro, Significados (s/d), "copiar trabalhos de outra pessoa, que já tenha [sido] feito, é considerado plágio, mesmo com o consentimento do autor". A mesma fonte indica que para evitar incorrermos em plágio, devemos identificar o autor ou fonte da informação e afirma que: "O ato do plágio, como consiste numa cópia da propriedade intelectual de outra pessoa, prejudica o desenvolvimento do pensamento crítico de um aluno, consequentemente retardando o seu aprendizado" (Significados, $s / d)$.

A utilização das referências, normalmente uma lista na parte final de um trabalho (como neste texto), lista as fontes utilizadas e permite o acesso às mesmas, com reconhecimento dos respetivos autores, evitando assim práticas de plágio. Por sua vez, no texto (como no exemplo do parágrafo anterior), as partes pertencentes a outros autores ou mesmo as ideias de terceiros, são reconhecidas de forma clara. Existem inúmeros fatores que levam os alunos a entregar trabalhos que não foram realizados por eles e, mesmo, a plagiar trabalho de terceiros, copiando até na íntegra a totalidade do trabalho ou partes de diversas fontes. As políticas associadas com o plágio e falha de conduta na entrega de trabalho que não seja resultante do esforço pessoal do aluno, tem vindo a ser reforçadas, bem como tornadas mais duras, as consequências. As medidas punitivas contra o plágio vão desde a perda de direito de avaliação, passando pela suspensão de matrícula e mesmo até à anulação ou expulsão da instituição de ensino. Em alguns casos podem mesmo originar processos legais. Não obstante, verificamos uma prática crescente quer da entrega de trabalhos não realizados pelo próprio, quer das práticas de plágio que podemos em conjunto designar por batota.

Com a facilidade de acesso à informação disponível na Internet, o plágio vem se tornando um problema crescente nos vários níveis de ensino, fundamental, médio e universidades e até mesmo em meio às pesquisas científicas. (AZEVÊDO, 2006; SABBATINI, 2013). "Na era da Internet, nunca foi tão fácil copiar o trabalho alheio, porém, também nunca foi tão fácil detectar essas cópias". (WAZLAWICK, 2014). Sendo assim, na tentativa de lidar com este problema, a Coordenação de Aperfeiçoamento de Pessoal de Nível Superior (CAPES) sugere seguir as diretrizes da Ordem dos Advogados de
Brasil (OAB) para o combate ao plágio nas instituições de ensino, com a utilização de softwares de deteç̧ão de plágio e de ações próprias das instituições para o combate (CAPES, 2011).

Com a pressão cada vez maior por publicações, sem que sejam oferecidas condições adequadas para tratar o plágio como um problema a ser resolvido, verifica-se que é preciso dar assistência pedagógica aos alunos, oferecer cursos de escrita acadêmica e estabelecer medidas punitivas claras em relação ao plágio (SABBATINI, 2013). Segundo Barbastefano e Souza (2007) e Silva (2008) existem várias causas para o plágio, tais como a facilidade de acesso à informação pela internet e os problemas de letramento visto que as escolas não ensinam aos alunos como fazer resumo e parafrasear textos, além da questão da existência da prática do plágio desde o ensino fundamental e médio.

Existem diversos estudos internacionais sobre plágio, tais como: Harvey e Robson, (2006); Scollon, (1995); Pecorari, (2001); Pennycook, (1994); Buranen, (1999); Shi, (2006); Bloch, (2001); Mckeever, (2004); Badge, (2010); sutherland-smith, (2005); dong, (1996); Flowerdew e Li, (2007) entre outros.

Podem ser encontrados também alguns estudos no Brasil, tais como:

Moraes, (2004) que tem como objetivo expor como fazer citações de acordo com a Associação Brasileira de Normas Técnicas (ABNT) e, sobretudo, por que fazer citações;

Silva (2008), que discute sobre o plágio no contexto acadêmico, com o objetivo de refletir sobre a necessidade de abrir espaços objetivos e subjetivos na universidade para que, na dialética entre o coletivo e o individual, a construção da autoria se efetive;

Pithan e Vidal (2012), que busca apresentar uma revisão bibliográfica do plágio considerada um fenômeno complexo, o qual necessita ser analisado de forma interdisciplinar e não apenas jurídica;

Vaz (2006), que trata de alguns aspectos das questões éticas envolvidas no uso da internet no ensino superior presencial, especificamente com relação ao plágio e a cópia;

Albuquerque (2009), que busca examinar alguns dos principais problemas relativos à produção textual em ciência, com ênfase para os considerados de má conduta; 
Job, Mattos e Trindade (2009), que analisam 191 pareceres referentes a manuscritos enviados a um periódico no período, de 1997 até 2007, com a finalidade de identificar os motivos que levaram os avaliadores à sua rejeição para publicação;

Azevêdo e Tavares-Neto, (2009) que tem como objetivo avaliar os destaques éticos existentes nas instruções aos autores de periódicos nacionais citados conjuntamente pelas quatro áreas médicas da CAPES e qualificados nível "A" nacional ou "I" internacional;

Abranches (2008), que discute a autoria nos trabalhos acadêmicos, particularmente dos discentes, no contexto da cibercultura.

Barbastefano e Souza (2007), verificam a percepção dos alunos de graduação quanto ao conceito de plágio e os conhecimentos acerca do assunto e suas implicações usuais e legais;

Silva e Domingues (2008) e Domingues e Fachini (2008), realizam o mesmo tipo de pesquisa de Barbastefano e Souza (2007), porém com alunos de Pós-Graduação.

Krokoscz, (2011), identifica diferentes abordagens sobre o plágio; compara as abordagens das melhores universidades mundiais com as universidades brasileiras e apresentar uma proposta de enfrentamento do plágio no Brasil.

Guedes e Filho (2015), avaliam o nível de conhecimento dos alunos matriculados no curso de odontologia da Universidade Estadual do Sudoeste da Bahia a respeito do tema plágio, da legislação pertinente ao tema, das fontes de pesquisa utilizadas e de como são tratados os direitos de reprodução de imagem.

\subsection{Implicações do plágio para quem aprende}

Podem ser listadas algumas razões que ajudam a perceber melhor o dano que as práticas de plágio ou de entrega de trabalhos não realizados pelos próprios, provoca. Este texto propõe-se apresentar com carácter pedagógico estes problemas, de forma a alertar para o problema do plágio e as suas consequências. A mensagem a passar é a de não fazer batota, pois terá consequências, mesmo que não descoberta (cada vez mais difícil, pois existe software especializada para detectar plágio e também a divulgação de trabalhos e a Internet torna muito mais possível que, mais cedo ou mais tarde, alguém aceda ou tome conhecimento da ocorrência de plágio). Também pelo dano na aprendizagem e na falha da criação de competências próprias, a prática do plágio tem consequências. Recentemente, um memorando sobre a batota no ensino superior aponta sete razões para não o fazer (Weimer, 2017):

Quando um aluno faz batota num exame, faz de conta que conhece o conteúdo, o que significa que quando for de futuro confrontado com esse material, terá que fingir o seu domínio. Como o conhecimento é cumulativo, o que não foi aprendido numa dada altura, pode dificultar a aprendizagem no momento seguinte. $\mathrm{O}$ conhecimento prévio acaba por facilitar o entendimento de muitos outros conteúdos, em especial os mais complexos, afetando a capacidade de adquirir novo conhecimento de forma expedita e eficaz. Adicionalmente, quando necessário esse conhecimento, terá mesmo de ser realizado um esforço (provavelmente) maior, com menos tempo e mais pressão do que o que seria necessário, quando comparado com a oportunidade de aprendizagem inicial.

Quando se engana, muitas das competências importantes, que os empregadores assumem que quem frequenta o ensino superior deve possuir, não existem ou são deficientes. Aprendemos novas competências a resolver problemas e não a copiar as respostas. Por exemplo, a escrita melhora, quando escrevemos e não quando se revê texto de outra pessoa. A capacidade para pensar de forma crítica, analisar argumentos e defender uma determinada posição são desenvolvidas pela sua realização e não quando se reproduz material de terceiros. Do mesmo modo que o treino desportivo de terceiros, não melhora a nossa capacidade, o trabalho realizado por terceiros, não desenvolve as nossas competências e a agilidade mental que um estudante de ensino superior adquire ao realizar, ele próprio, o trabalho que lhe é proposto.

Não nos devemos enganar: um pequeno problema de batota, raramente permanece pequeno ou escondido. Normalmente começa pequeno e discreto, mas logo cresce em algo grande e feio. Por exemplo, pode começar por espreitar as respostas num curso obrigatório para o qual não pretenda ter trabalho. Numa outra situação, decide copiar as respostas para o trabalho de suporte - talvez porque nesse momento, está com muito trabalho e ocupado e esse conteúdo será coberto novamente em situações posteriores. Decide enganar num curso de tópicos específicos, porque não usará o conteúdo na área onde se planeia trabalhar. 
Decide forjar os dados de um projeto, porque não é um estudo "real" de qualquer maneira. As estatísticas são claras: os alunos que enganam não fazem isso apenas uma vez ou em apenas em um curso. Fazem isso como uma prática recorrente. Aliás, quando mais caem nessa prática, mais frequente é a sua repetição.

Fazer batota no ensino superior leva a comportamentos idênticos em contexto profissional. Quem o faz assume que só o fará a estudar, mas a experiência diz o contrário, já que cria hábitos que dificilmente são esquecidos. Geralmente, aqueles que fazem batota enquanto estudam são mais propensos a enganar os seus empregadores ou empregados, a fugir aos impostos e a usar práticas comerciais antiéticas. Torna-se um hábito vitalício junto com a mentira que o cobre e com os esforços de ocultação do histórico dos processos seguidos.

Enganar nos estudos e na avaliação coloca a integridade pessoal em risco. Que tipo de pessoa se pretende ser? As ações tomadas no momento definem quem é e provavelmente em quem se tornará a pessoa que o pratica. Como se sente, quando alguém com quem se preocupa mente ou o tenta enganar? É possível ter essas pessoas em alta estima? A integridade pessoal é algo que usamos todos os dias da nossa vida. Pode e deve ser usado com orgulho ou sempre na expectativa de ser descoberto ou apontada alguma falha, cuja consequência e significado será (quase) sempre superior ao (pequeno) benefício de ter realizado determinada batota.

Em grande medida, avaliações e demais provas e trabalhos foram já realizadas por imensas pessoas, pelo que está ao alcance de se realizarem com sucesso, investido o trabalho necessário. Tal torna assim mais vantajoso e possível, alcançar os resultados sem batota. Alguns alunos enganam porque é mais fácil do que trabalhar para as notas - os argumentos já partilhados defendem que essa é uma lógica enviesada e de visão curta com potenciais graves consequências futuras, mas desculpa frequente de quem recorre a estas práticas de batota. Existem também situações em que os alunos enganam porque pensam que não possuem 0 que é necessário para obter os resultados pretendidos. No entanto, o sucesso no ensino superior é muito mais uma função dos hábitos de trabalho (e de estudo) do que do potencial de talento e inteligência que se possa possuir. Bons hábitos de estudo adquirem-se, pelo trabalho continuado. Comece com um curso e veja se os tempos de estudo curtos e regulares, sozinho ou com amigos e colegas, a frequência regular e o acompanhamento das aulas e trabalho autónomo (bem como leituras) acabam por fazer a diferença. Um dos maiores ensinamentos a reter do ensino superior é a capacidade de superação e a repetição dessa superação.

A batota impede que cada um de nós se possa tornar na pessoa desejada. Os graus académicos obtidos proporcionam uma sensação de realização, em especial, se obtidos por mérito e com o esforço próprio (o que ocorre na grande maioria dos casos). Eles são uma fonte de orgulho. Eles correspondem e confirmam as capacidades de uma pessoa. Graus académicos ganhos sem mérito, aparentemente fazem o mesmo, mas não proporcionam o conhecimento, nem a confiança para realizar atividade de forma autónoma, deixando a quem prevarica o gosto amargo de não conseguido algo e a permanente possibilidade de descoberta dessa falha.

\subsection{Software de detecção de plágio}

Existem atualmente bastantes programas de computador que facilitam a detecção de plágio. Alguns são para uso em aplicações, muitos estão associadas com a Web/Internet ou mesmo serviços Cloud. Existem programas de acesso livre, sem custos, e outros que exigem registo e possuem limitações ao uso. Outros ainda que tem de ser pagos e apresentam um nível de sofisticação maior. Muitas destas ferramentas estão limitadas à indicação de uma percentagem de semelhança de texto, mas algumas, produzem relatórios detalhados sobre onde e como o texto possui semelhanças. Propõe-se que os seguintes endereços sejam explorados, para conhecer as ofertas mais relevantes que estão disponíveis.

Exemplos de ferramentas que podem ser utilizadas sem custos:

Plagiarisma: http://plagiarisma.net

Copy

Spyder:

http://www.copyspider.com.br

Noplag: https://noplag.com/

Plagiarism

Check:

https://plagiarismcheck.org/

Existem ferramentas mais sofisticadas, mas com custos associados:

Grammarly: https://www.grammarly.com

Urkund: http://www.urkund.com/en/

Turnitin: http://turnitin.com/ 


\section{METODOLOGIA}

Nesta seção são apresentados os aspectos metodológicos utilizados na condução deste estudo. Esta pesquisa visa responder a seguinte pergunta de pesquisa "Como os alunos do curso de Sistemas de Informação entendem o plágio e quais as possíveis sugestões de ações para a redução desta prática?".

Este trabalho utiliza como método a pesquisa descritiva, pois segundo Gil (2008), este tipo de pesquisa procura descrever as características do fenômeno pesquisado ou de determinada população pesquisada. Utilizou-se de pesquisa de campo para coleta de dados por meio de questionário semiestruturados para identificar o nível de conhecimento sobre plágio acadêmico, compreendendo um total de vinte perguntas objetivas e três discursivas, cujas respostas se deram por escrito, na presença do pesquisador.

O questionário utilizado é uma adaptação do que foi utilizado por Guedes e Filho, para avaliar casos de plágio acadêmico entre alunos de odontologia, publicado em 2015. A população pesquisada constituiu-se de 37 alunos, devidamente matriculados no primeiro, terceiro e quinto período do curso de Sistemas de Informação do Instituto Federal de Goiás, no campus Luziânia.

O método de análise dos dados empregado consistiu primeiramente em utilizar o programa Microsoft Excel $2013^{\circledR}$, no qual se desenhou um banco de dados alimentado com os questionários respondidos. Em seguida, realizouse a análise descritiva das frequências das respostas dadas pelos discentes.

\section{ANÁLISE DOS RESULTADOS OBTIDOS}

Nesta seção são apresentados os principais resultados obtidos a partir do questionário aplicado aos 37 alunos matriculados no curso de Sistemas de Informação. Em relação às questões que avaliaram se os alunos tinham conhecimento sobre a definição de plágio segundo a legislação brasileira, $96,8 \%$ responderam que se trata de crime e apenas $3,2 \%$ que não configura crime, sendo que $96,7 \%$ concordam com a legislação vigente e apenas $3,3 \%$ não concordam, conforme pode se observar nas Figuras 1 e 2.
Figura 1. Conhecimento dos alunos sobre plágio.

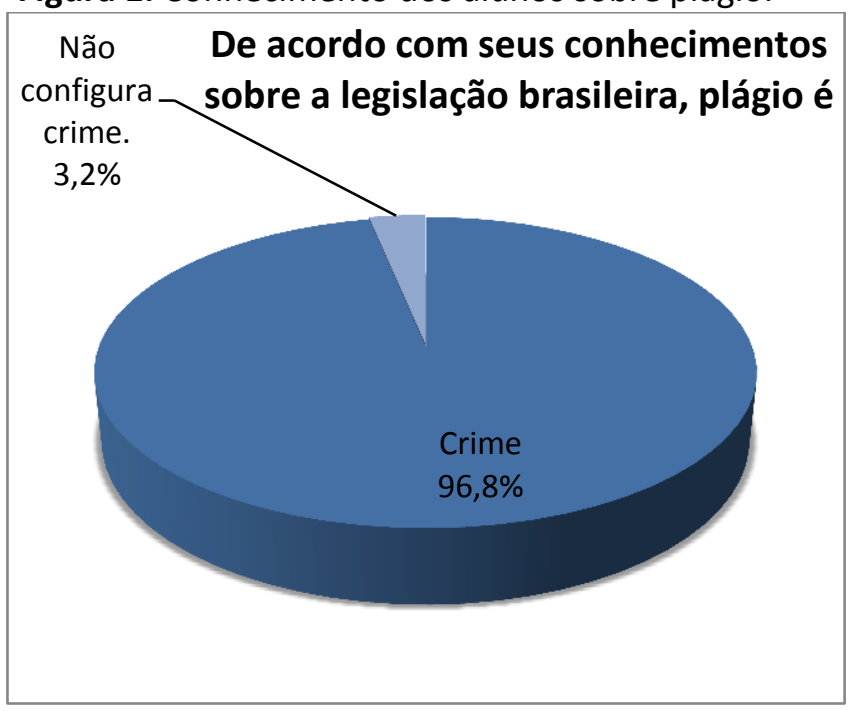

Figura 2. Conhecimento dos alunos sobre a legislação.

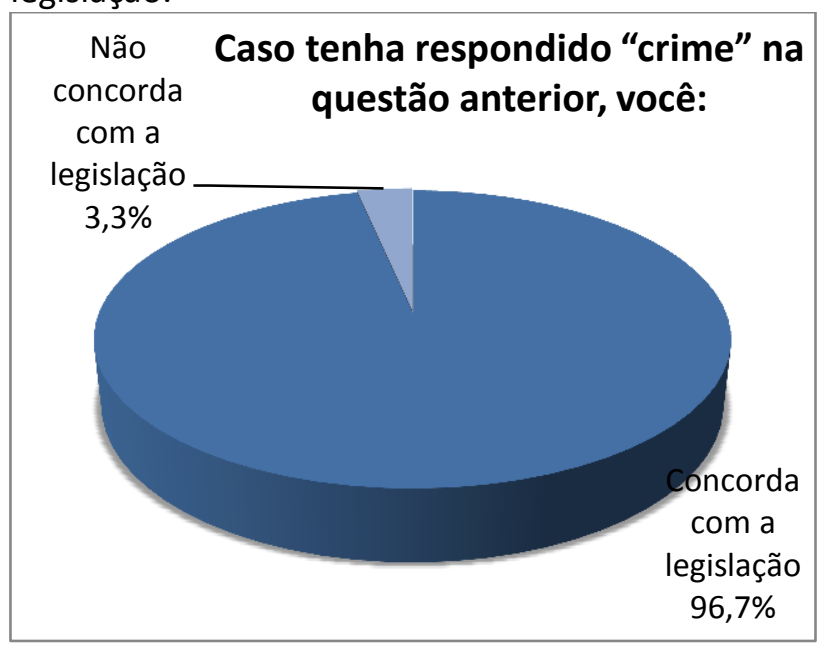

Ainda tratando da legislação, ao abordar em quais situações é permitida a reprodução parcial de uma obra intelectual. Do total de participantes, $71 \%$ responderam "Quando o dono dos direitos autorais autoriza a reprodução" e $22,6 \%$ "Quando o autor for devidamente referenciado", sendo que ambas estão corretas, $3,2 \%$ responderam "Quando a obra for de domínio público" e 3,2\% "Quando a reprodução for feita por um aluno de graduação", conforme apresentado na Figura 3. 
Figura 3. Conhecimento dos alunos sobre a legislação a respeito da reprodução.

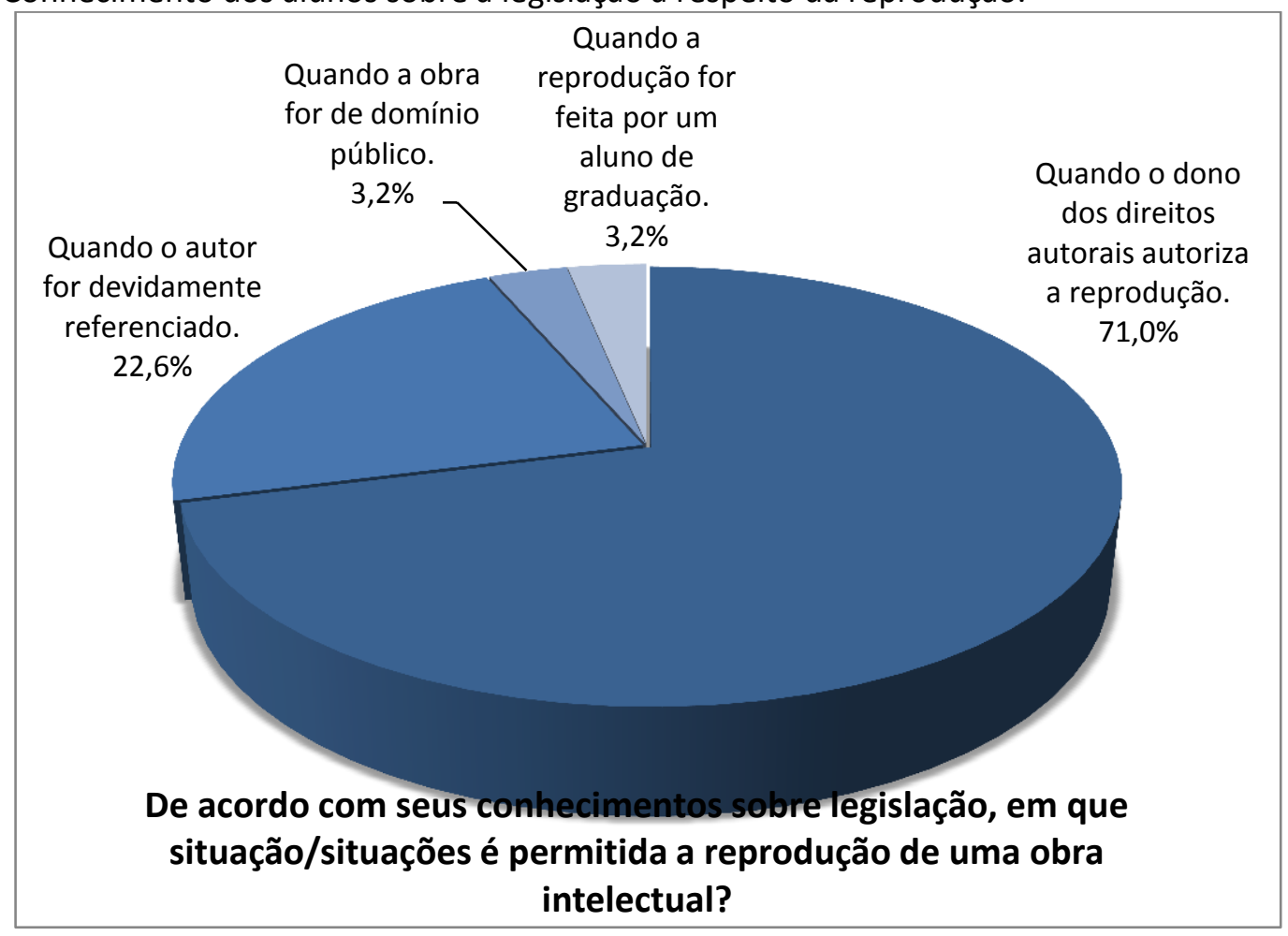

Para analisar as questões discursivas referentes ao conhecimento sobre os conceitos plágio, domínio público e paráfrase, foram criados categorias a partir das respostas mais frequentes. Os resultados podem ser observados o Quadro 1.

Quadro 1. Conhecimento dos alunos sobre o conceito de plágio, domínio público e paráfrase.

\begin{tabular}{|l|l|}
\hline \multicolumn{2}{|l|}{ O que você entende por plágio? } \\
\hline Cópia sem referência & $29 \%$ \\
\hline $\begin{array}{l}\text { Reprodução de uma obra sem } \\
\text { autorização do autor }\end{array}$ & $16,1 \%$ \\
\hline Cópia total ou parcial de uma obra & $54,9 \%$ \\
\hline O que você entende por domínio público? \\
\hline Obra que pode ser usada por todos & $61,3 \%$ \\
\hline Não sabe ou não respondeu & $38,7 \%$ \\
\hline O que você entende por paráfrase? \\
\hline $\begin{array}{l}\text { É utilizar fragmentos de textos } \\
\text { escritos por outros autores }\end{array}$ & $10,0 \%$ \\
\hline $\begin{array}{l}\text { É quando se lê um texto e se extrai } \\
\text { a ideia central }\end{array}$ & $13,3 \%$ \\
\hline $\begin{array}{l}\text { Reescrever, usando suas próprias } \\
\text { palavras. }\end{array}$ & $23,3 \%$ \\
\hline Não sabe ou não respondeu & $53,4 \%$ \\
\hline
\end{tabular}

Observa-se no Quadro 1 que sobre o entendimento de plágio, todos tentaram responder, e todos indicaram que é uma cópia, porém não tem muito conhecimento sobre os tipos de plágio.

Em relação ao conceito de domínio público o que se esperava como resposta era que esse é definido como toda obra científica, literária ou artística, com prazo expirado de proteção legal, cujos direitos econômicos não pertencem a ninguém. No Brasil o prazo é de 70 anos após a morte do autor. Porem os direitos morais de qualquer obra é eterno, precisando ser referenciadas eternamente para não configurar plágio (WAZLAWICK, 2014).

Pode-se perceber na Tabela 1, que muitos demonstraram desconhecer o conceito de domínio público, e a maioria confundiu com acesso do público às informações e obras. A paráfrase consiste na reprodução da ideia ou pensamento de um autor e transcrita com suas próprias palavras. Porém, necessita referenciar o autor. Observa-se na Tabela 1, que apenas 23,3\% souberam corretamente, mas não colocaram a necessidade de referenciar o autor. É importante destacar que $53,4 \%$ dos alunos não sabem o significado da palavra paráfrase.

Em relação ao tamanho que uma paráfrase pode ter, $64,3 \%$ de alunos acertaram, ao afirmar que "não existe tamanho máximo, depende do caso", conforme mostra a Figura 4. 
Figura 4. Conhecimento dos alunos sobre qual o tamanho máximo de uma paráfrase.

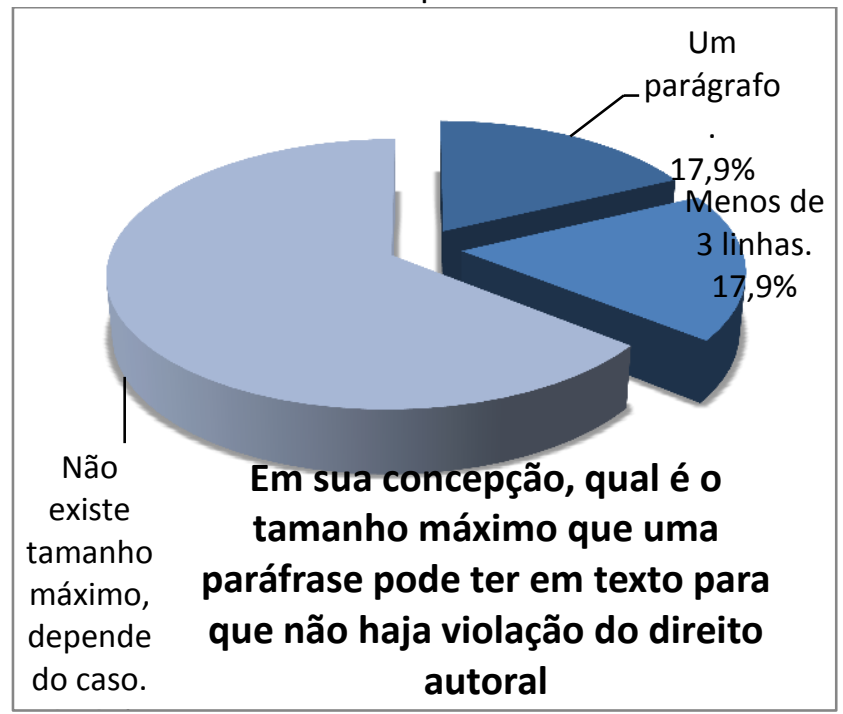

Para a pergunta "Quais fontes de pesquisa você utiliza regularmente para fazer seus trabalhos acadêmicos", as respostas encontradas foram: Biblioteca da universidade com $60,0 \%$, Internet, por meio de sites de busca com 26,7\%, Portal de Periódicos Capes com 10,0\% e Google Acadêmico com 3,3\%. Na Figura 5 observa-se que a biblioteca da universidade é a fonte mais utilizada.

Figura 5. Conhecimento dos alunos sobre as fontes utilizadas.

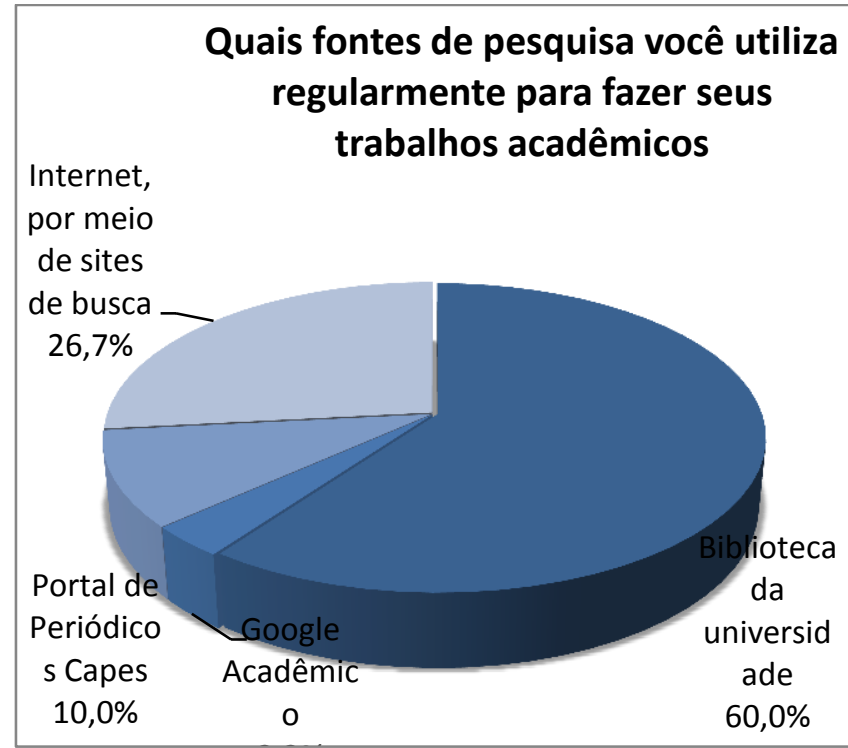

Quando questionados "Quais fontes de imagens você utiliza nas pesquisas?", a maioria dos alunos respondeu "Qualquer site que permita a utilização.", com 46,7\%, conforme apresentado na Figura 6.
Figura 6. Conhecimento dos alunos sobre as fontes de imagens utilizadas.

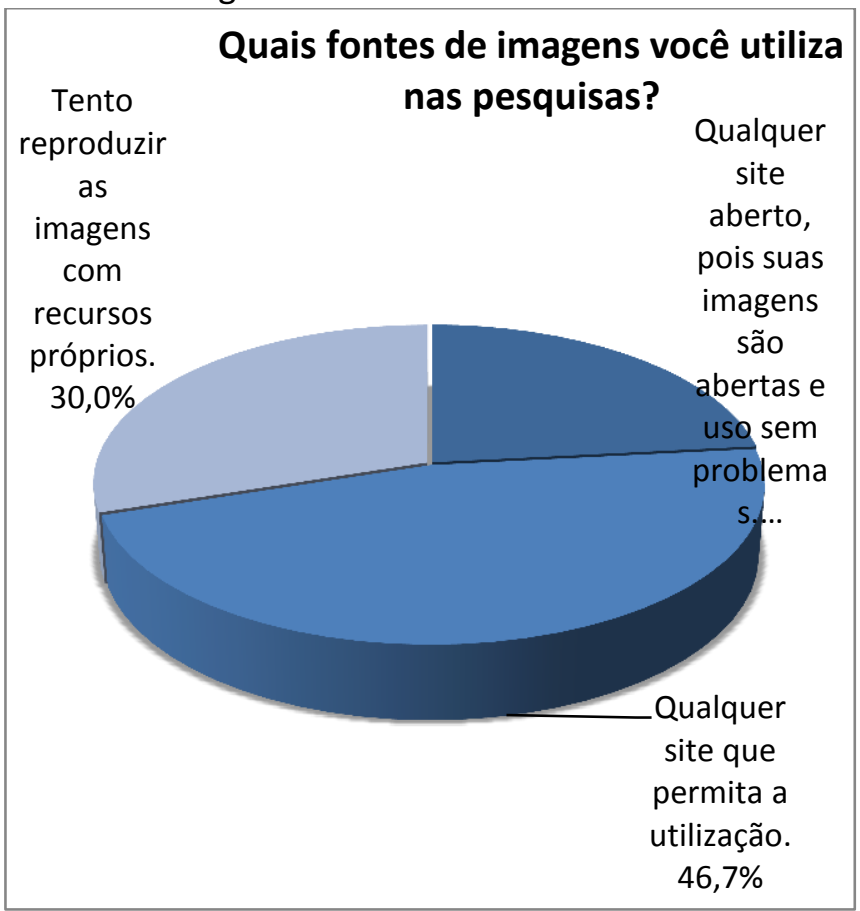

Na Figura 7, ao serem questionados se "Você já obteve informações de algum professor sobre plágio acadêmico?" a maioria, ou seja, 69\% afirmam que sim.

Figura 7. Conhecimento dos alunos sobre informações sobre plágio.

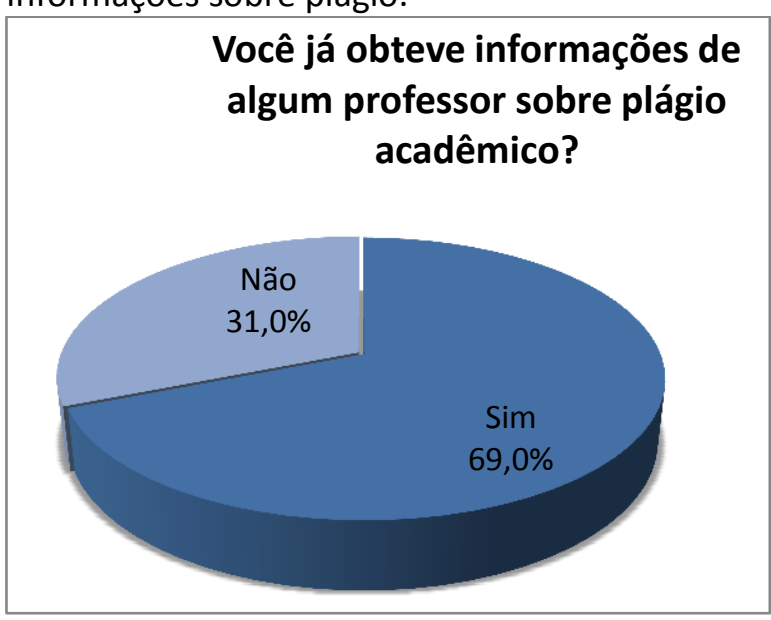

Observa-se na Figura 8, quando questionados de quais os "Motivos que mais influenciam a ocorrência de plágio", mais da metade, 56,7\%, responderam ser por facilidade de copiar da internet. Seguido por "Ausência de normas de controle e punição da prática do plágio", com 20,0\%. 
Figura 8. Conhecimento dos alunos sobre os motivos para ocorrência de plágio.

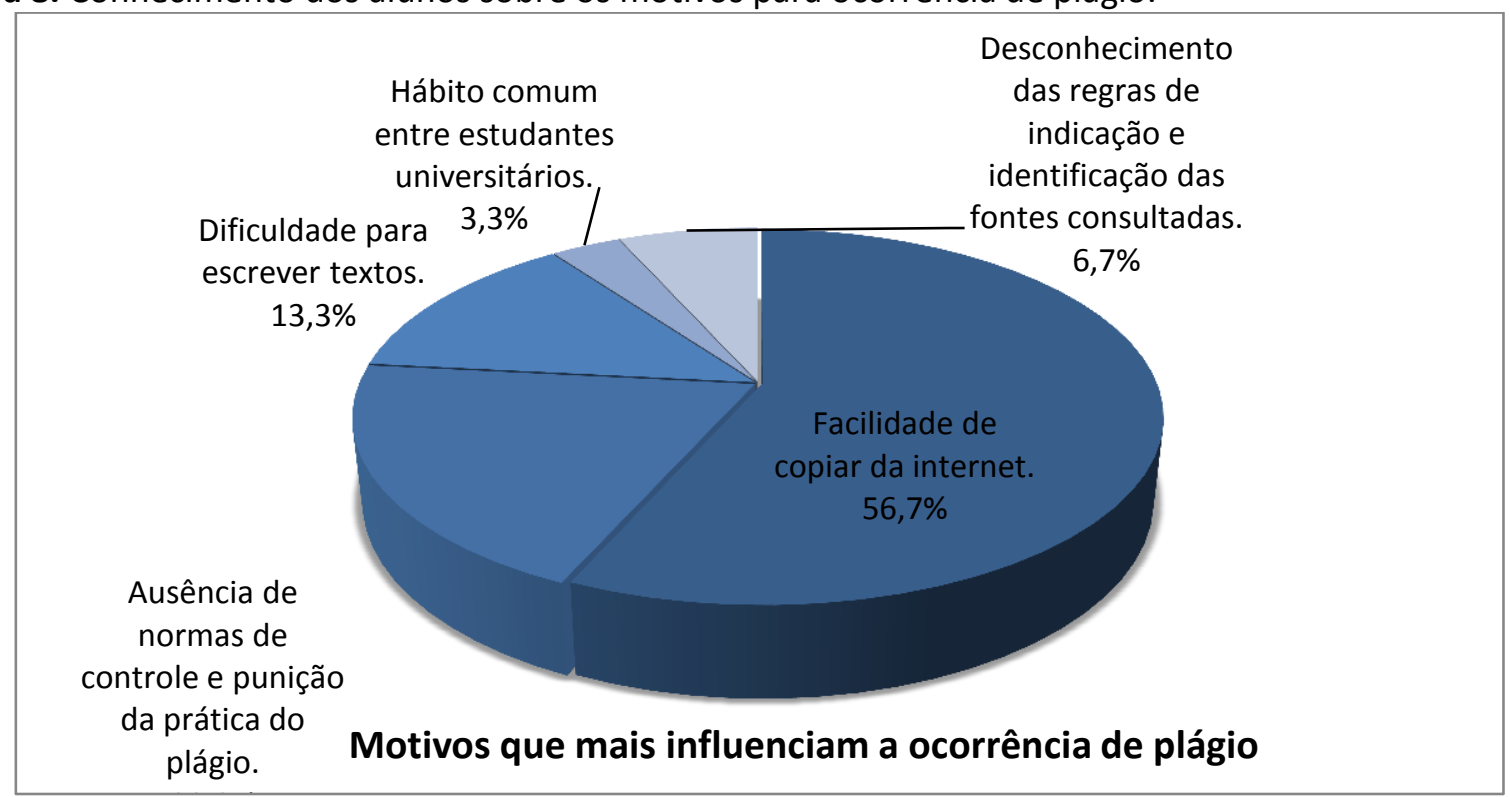

Em relação às "ações adotadas pelas instituições nas quais você estudou que tinham a finalidade de informar e orientar os estudantes para que o plágio acadêmico fosse evitado." Pode-se observar que as opções "regulamentos, regras e sanções claramente divulgadas aos alunos." e "Não me lembro de nenhuma

atividade específica da instituição que tenha sido adotada visando à informação e a orientação para que os estudantes evitassem a ocorrência de plágio acadêmico." ficaram empatadas com $38,5 \%$, conforme apresentado na Figura 9.

Figura 9. Conhecimento dos alunos sobre as ações para evitar o plágio.

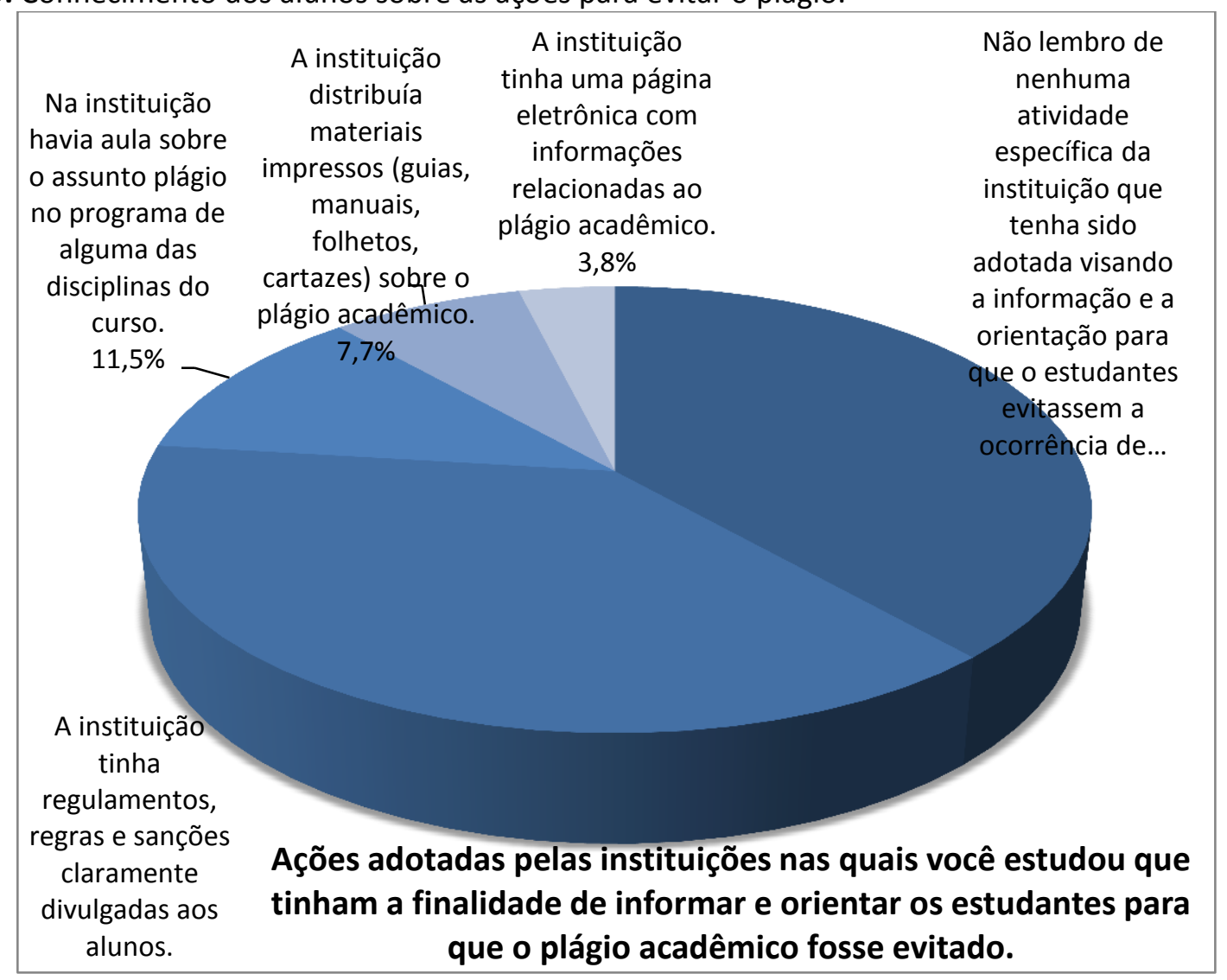


Por fim, questionados "Em sua opinião qual ação é mais eficiente para prevenir o plágio nas atividades acadêmicas?", a Figura 10 mostra que "Ações educativas sobre a prevenção de plágio, tais como: aulas, palestras, seminários etc." como a melhor forma com $44,8 \%$.

Figura 10. Conhecimento dos alunos sobre as ações para prevenir o plágio nas atividades.

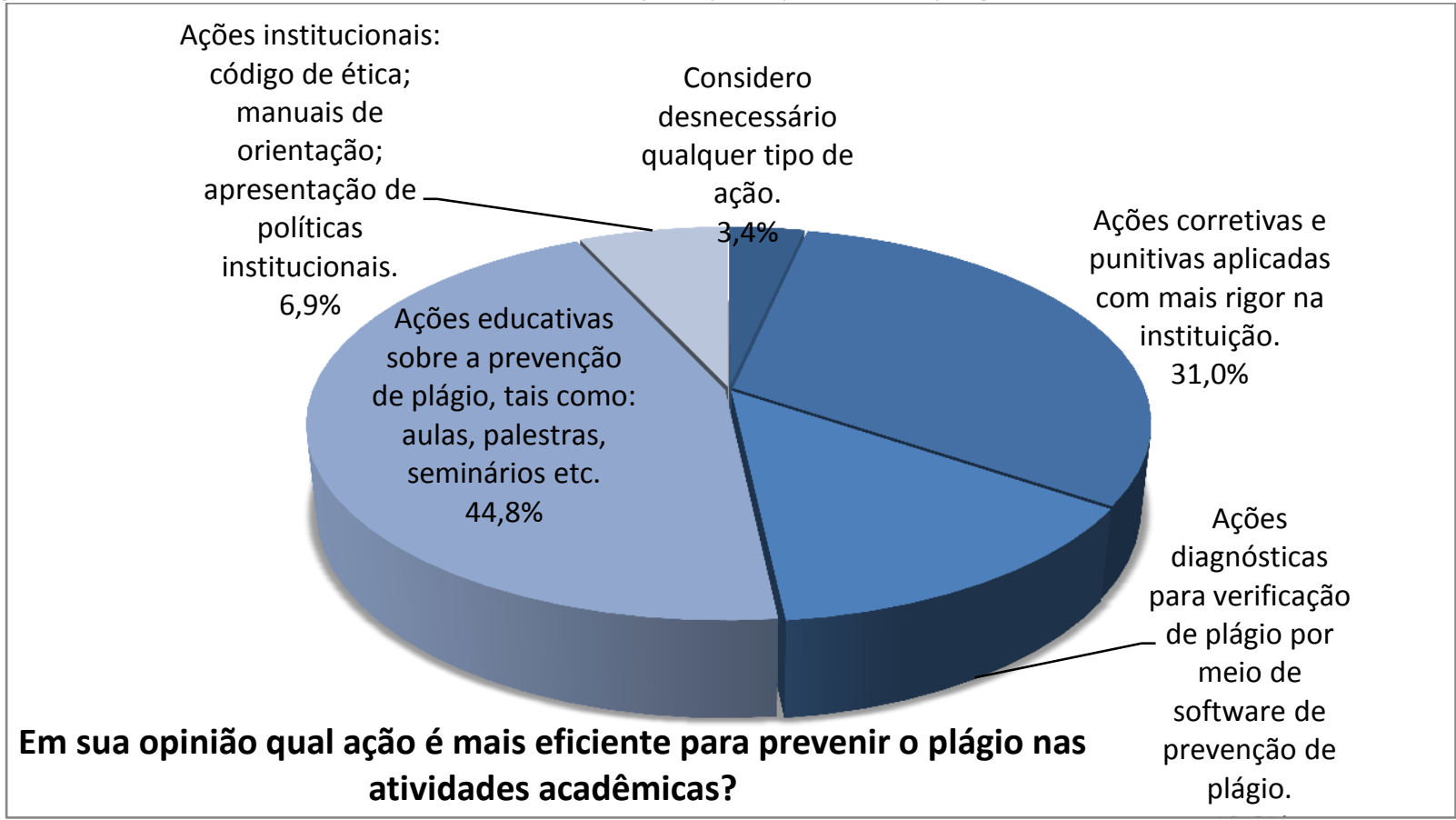

\section{CONSIDERAÇÕES FINAIS}

Esta seção tem por objetivo realçar as principais conclusões decorrentes do estudo realizado. Com o intuito de proporcionar uma melhor compreensão dos resultados encontrados são retomados a questão de pesquisa e o objetivo do artigo. A questão de pesquisa do presente artigo é "Os alunos do curso de Sistemas de Informação entendem o que é plágio e quais são as suas possíveis sugestões de ações para a redução desta prática?".

Assim, para a realização da pesquisa, foi definido o objetivo deste estudo que consistiu em verificar junto a alunos do curso de Sistemas de Informação, como estes entendem o plágio e principalmente quais as possíveis ações para a redução desta pratica nos trabalhos acadêmicos. Sendo assim, foi realizada uma pesquisa de campo para coleta de dados por meio de questionário semiestruturados, com 37 alunos do curso de Sistemas de Informação, para identificar o nível de conhecimento sobre plágio acadêmico. Utilizou-se para isso o método de pesquisa descritiva e análise descritiva dos dados.
Os resultados obtidos permitiram concluir que os alunos do curso de Sistemas de Informação não têm conhecimento pleno do que é plágio, mesmo sendo um assunto discutido na vida acadêmica, a maioria não soube responder com clareza aos questionamentos feitos. Pode-se notar que eles sabem que o plágio é crime e que pode acarretar em sanções, porém não souberam identificar os tipos de plágios específicos, nem o uso correto e a necessidade das citações diretas e indiretas.

Em relação à realização da pesquisa, a maior parte dos alunos declarou utilizar fontes confiáveis de pesquisa, mas não apresentam a mesma preocupação em relação à utilização de imagens, não solicitando permissão para o uso de imagens protegidas ou produzindo suas próprias imagens. Como possíveis ações para a redução das práticas de plágio nos trabalhos acadêmicos obteve-se: adoção de regulamentos, regras e sanções claramente divulgadas aos alunos e ações educativas sobre a prevenção de plágio, tais como: aulas, palestras, seminários, entre outros. 
O estudo limitou-se a analisar o plágio e as possíveis ações para a redução desta prática a partir de pesquisa realizada com acadêmicos de um curso de Sistemas de Informação, o que implica impossibilidade de generalização dos resultados. As abordagens teóricas, juntamente com as constatações empíricas encontradas trouxeram contribuições para o contexto acadêmico, tanto para pessoas como para instituições, que podem contar com este estudo para elaboração de novas ações relativas a plágio.

Diante dos resultados obtidos e da relevância do tema, evidenciou-se a necessidade de ampliar esta pesquisa a outros cursos de diversas outras áreas dessa e de outras universidades, de forma a obter um levantamento efetivo de como esse assunto está sendo abordado nos cursos de graduação e pósgraduação em todo o país.

\section{REFERÊNCIAS}

ABRANCHES, S. P. O que fazer quando eu recebo um trabalho CTRL C + CTRLV? Autoria, Pirataria e Plágio na Era Digital: desafios para a prática docente. In: SIMPÓSIO HIPERTEXTO E TECNOLOGIAS NA EDUCAÇÃO: MULTIMODALIDADE E ENSINO. 2., 2008, Recife. Anais Eletrônicos [...]. Recife, PE: Ed. UFPE, 2008.

ALBUQUERQUE, U. P. A qualidade das publicações científicas: considerações de um editor de área ao final do mandato. Acta Botânica Brasilica, v. 23, p. 292-296, 2009. https://doi.org/10.1590/S0102-

$\underline{33062009000100031}$

AZEVÊDO, E. S. Honestidade científica: outro desafio ao controle social da ciência. Gazeta Médica da Bahia, v. 76, n. 1, p. 35-41, 2006.

AZEVÊDO, E. S.; TAVARES-NETO, J. Destaques éticos nos periódicos nacionais de áreas médicas. Revista da Associação Médica Brasileira, v. 554, p. 400-404, 2009. https://doi.org/10.1590/S0104$\underline{42302009000400013}$

BADGE, J. How effective are electronic plagiarism detection systems and does it matter how you use them? Reviewing the evidence. In: CONFERÊNCIA INTERNACIONAL SOBRE PLÁGIO 4., 2010. Anais [...]. 2010.

BARBAStefanO, R. G.; SOUZA, C. G. Percepção do conceito de plágio acadêmico entre alunos de engenharia de produção e ações para a sua redução. Revista Produção On Line, Florianópolis, p. $1-18,2007$. https://doi.org/10.14488/1676-1901.v7i4.52

$B L O C H$, J. Plagiarism and the ESL student: From printed to electronic texts. In: belcher, d.; hirvela, a. (Eds.). Linking literacies: perspectives on L2 reading-writing connections. Ann Arbor, MI: University of Michigan Press, p. 209-228, 2001.

BURANEN, L. But I wasn't cheating: plagiarism and cross-cultural mythology. In: ROY, A..; BURANEN, I. (eds). Perspectives on plagiarism and intellectual property in a postmodern world. Albany, NY: Suny $P_{,}$, 1999. p. 63-74.

DOMINGUES, M. J. C. DE S.; FACHINI, G. J. Percepção do plágio acadêmico entre alunos de programas de pós-graduação em administração e contabilidade. In: SEMINÁRIO DE ADMINISTRAÇÃO - SEMEAD, 12., São Paulo. Anais [...].São Paulo: SEMEAD, 2008.

DONG, Y. R. Learning how to use citations for knowledge transformation: non-native doctoral students' dissertation writing in science. Research in the Teaching of English, v. 30, p. 428457, 1996.

FERREIRA, M. M.; PERSIKE, A. O tratamento do plágio no meio acadêmico: O caso USP. REVISTA SIGNÓTICA, v. 26, n. 2, p. 519-540, 2014. https://doi.org/10.5216/sig.v26i2.30312

FLOWERDEW, J.; LI, Y. Plagiarism and second language writing in an electronic age. Annual Review of Applied Linguistics, v. 27, p. 161-183, 2007.

\section{https://doi.org/10.1017/S0267190508070086}

GIL, A. C. Como elaborar projetos de pesquisa. São Paulo: Atlas, 2008.

GUEDES. D. O; GOMES FILHO. D. L. Percepção de plágio acadêmico entre estudantes do curso de odontologia. Rev. bioét. (Impr.). v. 23, p. 139-48, $2015 . \quad$ https://doi.org/10.1590/1983$\underline{80422015231054}$

HARVEY, J.; ROBSON, S. The accidental plagiarist: an institutional approach to distinguishing between a deliberate attempt to deceive and 
poor academic practice. In: CONFERÊNCIA INTERNACIONAL SOBRE PLÁGIO, 2., 2006.

JOB, I.; MATTOS, A. M.; TRINDADE, A. Processo de revisão por pares: por que são rejeitados os manuscritos submetidos a um periódico científico? Movimento, v. 15, n. 3, p. 35-55, 2009. https://doi.org/10.22456/1982-8918.8830

KROKOSCZ, M. Abordagem do plágio nas três melhores universidades de cada um dos cinco continentes e do Brasil. Revista Brasileira de Educação, v. 16, n. 48, p. 745-818, 2011. https://doi.org/10.1590/S1413-

$\underline{24782011000300011}$

MCKEEVER, L. Online plagiarism detection services: saviour or scourge? CONFERÊNCIA INTERNACIONAL SOBRE PLÁGIO, 1., 2004.

MORAES, R. O plágio na pesquisa acadêmica: a proliferação da desonestidade intelectual. Revista Diálogos Possíveis, Faculdade Social da Bahia, Bahia, n. 1, p. 92-109, 2004.

PECORARI, D. Plagiarism and international students: How the english-speaking university responds. In: CELCHER, D.; HIRVELA, A. (eds.). Linking literacies: perspectives on $L 2$ readingwriting connections. Ann Arbor: University of Michigan Press, 2001.

PENNYCOOK, A. The complex contexts of plagiarism: a reply to Deckert. Journal of Second Language Writing, v. 3, p. 277-284, 1994. https://doi.org/10.1016/1060-3743(94)90020-5

PITHAN, L. H.; VIDAL, T. A. O plágio acadêmico como um problema ético, jurídico e pedagógico. Direito \& Justiça, Porto Alegre, 2012.

PRIBERAM Definição de plágio. Dicionário Priberam. Disponível em https://www.priberam.pt/dlpo/batota. Acesso em: 19 / jan. 2018.

PRIBERAM. Definição de plágio. Dicionário Priberam. Disponível em:https://www.priberam.pt/dlpo/plagio. Disponível em 19 jan. 2018.

SABBATINI, M. Do plágio à publicidade disfarçada: brechas da fraude e do antiético na comunicação científica. Revista ComCiência, Unicamp, v. 1, 2013.

SCOLLON, R. Plagiarism and ideology: Identity in intercultural discourse. Language in Society, $v$. 24, p. 1-28, 1995.

https://doi.org/10.1017/S0047404500018388

SHI, L. Cultural backgrounds and textual appropriation. Language Awareness, v. 15, p. 264-282, 2006. https://doi.org/10.2167/la406.0

SIGNIFICADOS. Significado de Plágio. Significados. Disponível em https://www.significados.com.br/plagio/.Acesso em: 19 jan. 2018.

SILVA, A. K. L.; DOMINGUES, M. J. C. S. Plágio no meio acadêmico: de que forma alunos de pósgraduação compreendem 0 tema. Revista Perspectivas Contemporâneas, Campo Mourão, v. 3, n. 2, p. 117-135, 2008.

SILVA, O. S. F. Entre o plágio e a autoria: qual o papel da universidade? Revista Brasileira de Educação, v. 13 n. 38, p. 357-414, 2008. https://doi.org/10.1590/S1413-

$\underline{24782008000200012}$

SUTHERLAND-SMITH, W. Retribution, deterrence and reform: the dilemmas of plagiarism management in universities. Journal of Higher Education Policy and Management, v. 32, n. 1, p. 5-16, 2005. https://doi.org/10.1080/13600800903440519

VASCONCELLOS, S. M. R. O plágio na comunidade científica: questões culturais e linguísticas. Ciência e Cultura, v. 59, n. 3, p. 4-5, 2007.

VAZ, T. R. D. O avesso da ética: a questão do plágio e da cópia no ciberespaço. Cadernos de Pós-Graduação, Educação, São Paulo, v. 5, n. 1, , p. 159-172, 2006. https://doi.org/10.5585/cpg.v5n1.1853

WAZLAWICK, R. S. Metodologia de pesquisa para ciência da computação. 2.ed.. Rio de Janeiro: Elsevier, 2014.

WEIMAR, M. A Memo to Students on Cheating. Faculty Focus. Post on January 17. 2017. Disponível em:https://www.facultyfocus.com/articles/teachi 
ng-professor-blog/memostudents-cheating/.

Acesso em: 19 jan. 2018. 